\title{
Salt and cardiovascular disease
}

\author{
Legislation to cut levels of salt in processed food is necessary and justified
}

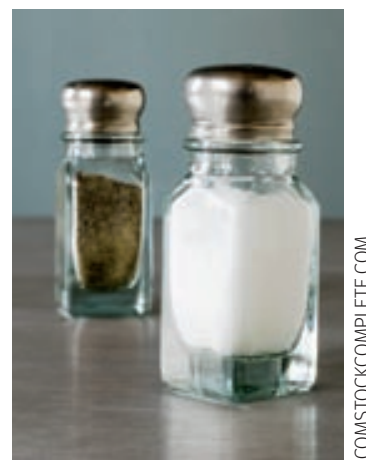

\section{RESEARCH, p 885}

\section{Francesco P Cappuccio chair} of cardiovascular medicine and epidemiology, Warwick Medical School, Coventry

cvme@warwick.ac.uk

Competing interests: None declared. Provenance and peer review: Commissioned; not externally peer reviewed.

BMJ 2007;334:859-60 doi:10.1136/bmj39175.364954.BE
Blood pressure is the most powerful predictor of stroke and other cardiovascular events. The importance of salt (sodium chloride) intake in determining blood pressure and the incidence of hypertension is well established. Furthermore, randomised controlled clinical trials of moderate reductions in salt intake show a dose dependent cause-effect relation and lack of a threshold effect within usual levels of salt intake in populations worldwide. ${ }^{1}$ The effect is independent of age, sex, ethnic origin, baseline blood pressure, and body mass.

Prospective studies, ${ }^{2-5}$ with one exception, ${ }^{6}$ also indicate that higher salt intake predicts the incidence of cardiovascular events. While widespread support exists for reducing salt intake to prevent cardiovascular disease, the lack of large and long randomised trials on the effects of salt reduction on clinical outcomes has encouraged some people to argue against a policy of salt reduction in populations. ${ }^{6}$

In this week's $B M J$, Cook and colleagues ${ }^{7}$ report the long term effects of reduced dietary sodium on cardiovascular disease in people participating in the controlled randomised trials of hypertension prevention follow-up studies (TOHP I and II). More than 3000 participants without hypertension were randomised to a reduced sodium intake for 18 months (TOHP I) or 36-48 months (TOHP II), or to a control arm. The reductions in sodium intake were $44 \mathrm{mmol} /$ day and $33 \mathrm{mmol} /$ day (equivalent to $\sim 2.6 \mathrm{~g}$ and $\sim 2.0 \mathrm{~g}$ of salt), respectively. The results show that people originally allocated to either sodium reduction group had a 30\% lower incidence of cardiovascular events in the next 10-15 years, irrespective of sex, ethnic origin, age, body mass, and blood pressure. The benefits exceed those estimated by a recent meta-analysis. ${ }^{8}$ Cook and colleagues' study is the first to report a beneficial effect of dietary salt reduction on cardiovascular outcomes based on randomised trial data.

The study strengthens the support for dietary recommendations for lower salt intake to prevent cardiovascular disease in the general population. In 1985, the World Health Organization recommended that the average salt intake should be reduced to $5 \mathrm{~g}$ per day or less. However, few countries have policies for targeted reduction in salt intake.

Differences exist between developed and developing countries. In Westernised countries, people derive salt mostly from bread and processed food and only a small proportion comes from discretionary use (up to 20\%). A population wide policy of salt reduction in developed countries can only be implemented with the collaboration of the food industry. Over the years, however, the need to sustain a profitable market has led to opposition from the food industry or slow progress. ${ }^{9}$

In England and Wales some progress has been made, but levels of salt intake are still far from the government's recommended $6 \mathrm{~g}$ of salt per day. Future options are to do nothing, to establish voluntary target levels of salt for a wide range of foods, or to legislate so that the food industry has to comply. Given the inertia of the past 20 years, the first option would not contribute to progress. The "voluntary" option would support existing work, but it is unlikely to achieve the set targets. The recent position of the industry in rejecting the "traffic light" proposal for labelling, whereby highly salted foods would carry a red alert warning, is one measure of the gap still remaining. The legislation option would require the food industry to reduce the salt content of processed food to within set levels. The experience in Finland suggests that legislation has added value to the previous option and at this stage is necessary and justified.

Conversely, in many developing countries, like those of sub-Saharan Africa, where the main source of salt is still discretionary, community based and context specific initiatives can be effective and should be pursued, ${ }^{10}$ given the increasing burden of cardiovascular disease related to hypertension.

Without considerably modifying the environment by allowing greater availability of low salt foods, people in developed countries will find it difficult to exercise their "choice" when trying to reduce dietary salt. Doctors and health professionals have long used dietary counselling to deliver non-pharmacological management of hypertension. Advising patients to reduce salt intake with a lifestyle package quickly delivered in a busy primary care setting is ineffective, however. ${ }^{11} \mathrm{~A}$ baseline assessment of salt intake (through a $24 \mathrm{~h}$ urinary collection for the measurement of sodium) is not part of the UK's National Service Framework requirements and is not included in the Quality and Outcome Framework. The current system is therefore unlikely to make health professionals and consumers more aware of how much salt people eat or to increase motivation and knowledge on how to reduce it. In a climate of scarce healthcare resources, one of the most cost effective ways to reduce the burden of cardiovascular disease is being overlooked. ${ }^{12}$ And yet the evidence gets stronger. 
1 He FJ, MacGregor GA. How far should salt intake be reduced? Hypertension 2003;42:1093-9.

2 Sasaki S, Zhang X-H, Kesteloot H. Dietary sodium, potassium, saturated fat, alcohol and stroke mortality. Stroke 1995;26:783-9.

3 He J, Ogden LG, Vupputuri S, Bazzano LA, Loria C, Whelton PK. Dietary sodium intake and subsequent risk of cardiovascular disease in overweight adults. JAMA 1999;282:2027-34

4 Tuomilehto J, Jousilahti P, Rastenyte D, Moltchanov V, Tanskanen A, Pietinen P, et al. Urinary sodium excretion and cardiovascular mortality in Finland: a prospective study Lancet 2001:357:848-51.

5 Nagata C, Takatsuka N, Shimizu N, Shimizu H. Sodium intake and risk of death from stroke in Japanese men and women. Stroke 2004;35:1543-7.

6 Cohen HW, Hailpern SM, Fang J, Alderman MH. Sodium intake and mortality in the NHANES II follow-up study. Am J Med 2006;119:275 e7-14.

7 Cook NR, Cutler JA, Obarzanek E, Buring JE, Rexrode KM, Kumanyika $\mathrm{SK}$, et al. Long term effects of dietary sodium reduction on cardiovascular disease outcomes: observational follow-up of trials of hypertension prevention. BMJ 2007 doi: 10.1136/ bmi.39147.604896.55.

8 He FJ, MacGregor GA. Effect of modest salt reduction on blood pressure: a meta-analysis of randomized trials. Implications for public health. J Hum Hypertens 2002;16:761-70.

9 Karppanen H, Mervaala E. Sodium intake and hypertension. Prog Cardiovasc Dis 2006;49:59-75.

10 Cappuccio FP, Kerry SM, Micah FB, Plange-Rhule J, Eastwood JB. A community programme to reduce salt intake and blood pressure in Ghana. BMC Public Health 2006;6:13.

11 Little P, Kelly J, Barnett J, Dorward M, Margetts B, Warm D. Randomised controlled factorial trial of dietary advice for patients with a single high blood pressure reading in primary care. BMJ 2004;328:1054-7.

12 Selmer RM, Kristiansen IS, Haglerod A, Graff-Iversen S, Larsen $\mathrm{HK}$, Meyer HE, et al. Cost and health consequences of reducing the population intake of salt. J Epidemiol Community Health 2000;54:697-702

\section{Postmenopausal hormone therapy}

\section{Symptoms should be treated with lowest effective dose of hormone therapy for the shortest time possible}

\section{SHORT CUTS, p 872}

\section{Deborah Grady professor of} medicine, University of California San Francisco and San Francisco VA Medical Center, San Francisco, CA 94115, USA

Deborah.Grady@ucsf.edu Elizabeth Barrett-Connor professor and chief, Division of Epidemiology, Department of Family and Preventive Medicine, University of California, San Diego School of Medicine, San Diego, California, 92093, USA

Competing interests: DG has received research support from Berlex, Bionovo, Eli Lilly, and Pfizer. EB-C has received research support from NIH, Amgen, Lilly, Merck, Wyeth, Proctor and Gamble, Roche, and GlaxoSmithkline.

Provenance and peer review: Commissioned; not externally peer reviewed.

BMJ 2007;334:860-1 doi:10.1136/bmi39185.380405.BE
In March 2007, the North American Menopause Society (NAMS) published an updated position statement on the use of hormone therapy in postmenopausal women. ${ }^{1}$ NAMS recommends hormone therapy, which is a highly effective treatment for hot flushes and vaginal atrophy, ${ }^{2}$ as first line treatment for women with moderate to severe symptoms. It is also effective for preventing osteoporotic fractures, ${ }^{34}$ but NAMS recommends that hormone therapy for this purpose should be weighed against potential harm and that other approved preventive treatments such as bisphosphonates should be considered. These recommendations are clear, simple, and based on solid evidence from many randomised controlled trials.

However, NAMS recommendations are less clear in several other areas. For example, after clearly stating that hormone therapy increases risk of venous thromboembolic events and stroke, no advice is provided about how clinicians and patients should use this information. Similarly, NAMS notes that risk of breast cancer is increased in women who use oestrogen plus progestin for five years or more, but no recommendation is given about its use in women at high risk of breast cancer. The statement also notes that treatment with hormone therapy in women over 65 years increases risk for dementia, ${ }^{56}$ and that no evidence is available regarding effects on dementia from clinical trials in younger women, but there is no clear statement that hormone therapy should not be used to prevent dementia.

NAMS published a position statement on use of postmenopausal hormone therapy in 2004, and since then no large randomised trials have been published that would require revision of guidelines. What then has changed since the earlier statement? The main changes in the new position statement reflect the belief of NAMS panelists that, if used during or shortly after the menopause, hormone therapy may not increase risk of coronary heart disease. Evidence to support this "timing hypothesis" comes from studies of castrated animals and post hoc analyses of observational studies, but primarily rests on subgroup analyses of data from the two women's health initiative randomised trials. ${ }^{7}$ Analyses that pooled data from the women's health initiative trial of oestrogen alone and of oestrogen plus progestin show no clear difference in risk for coronary heart disease associated with use of hormone therapy in women in their 50s compared with older women. However, women treated with hormone therapy within 10 years of the menopause seemed to have a reduced risk of heart disease (hazard ratio 0.76 , $95 \%$ confidence interval 0.50 to 1.16 ), whereas those who had undergone the menopause more than 20 years ago had an increased risk $(1.28,1.03$ to 1.58 ; $\mathrm{P}$ value for interaction 0.02). These data are not entirely convincing, as about 137 comparisons were performed, and several statistically significant findings would be expected to occur by chance. The "timing hypothesis" will probably

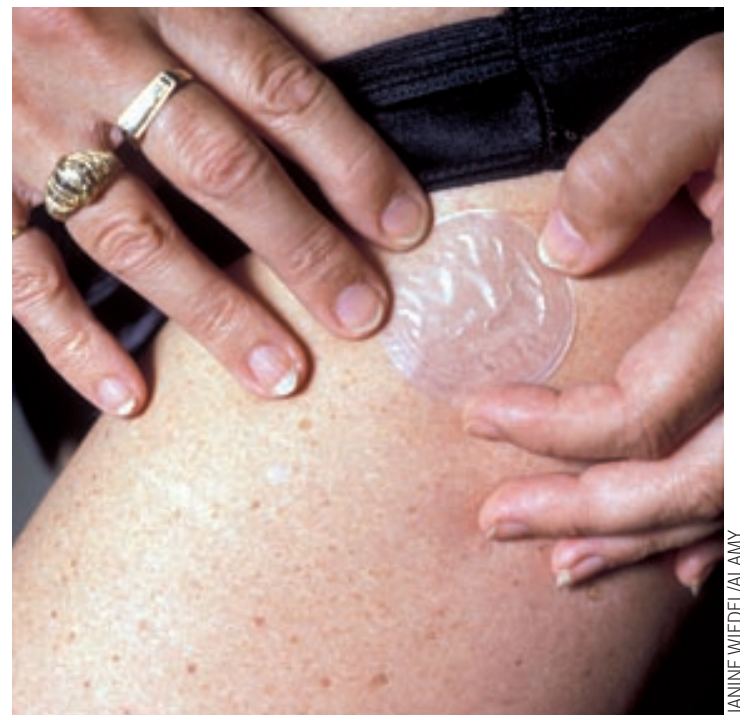


never be directly confirmed or refuted, because the low absolute rate of coronary heart disease among perimenopausal women would require many thousands of perimenopausal and early postmenopausal women to be randomised to treatment or placebo for more than a decade. Even if the timing hypothesis is true, little evidence exists that other risks of hormone therapy vary with time since menopause. ${ }^{7}$ Finally, the timing hypothesis has little impact on clinical care. Even if we reject the timing hypothesis and assume that the overall risks documented in the women's health initiative trials apply to younger women, the absolute risk associated with taking hormone therapy for a few years to treat menopausal symptoms is low, and worth the benefit of symptom relief.

The NAMS position statement is not an evidence based guideline as defined by the UK National Institute for Health and Clinical Excellence ${ }^{8}$ or the US Preventive Services Task Force..$^{9}$ A search of Medline (but not other databases) was performed, but data were not systematically abstracted or synthesised. References are provided in a bibliography, but it is not possible to determine which studies were used to support specific recommendations. NAMS uses a consensus process, in which selected experts are given recent references and asked to provide their opinions. The position statement is based on agreement among at least two thirds of the panel-more a majority than a consensus. NAMS is to be congratulated for providing financial disclosures of panel members, but it is concerning that these are so extensive.

Another worrying aspect of the 2007 NAMS position statement is that it suggests that use of postmenopausal hormone therapy is complicated. While some details are unclear or complex, the basic approach to using postmenopausal hormone therapy is clear and simple: treat bothersome menopausal symptoms with the lowest effective dose of hormone therapy for the shortest time possible and do not use it to prevent disease.

1 Estrogen and progestogen use in peri- and postmenopausal women: March 2007 position statement of the North American Menopause Society. Menopause 2007;14:1-17.

2 Nelson HD, Haney E, Humphrey L, Miller J, Nedrow A, Nicolaidis C, et al. Management of menopause-related symptoms. Evidence Report/ Technol Assessment No 120. Rockville, MD: Agency for Healthcare Research and Quality, 2005.www.ahrq.gov/clinic/epcsums menosum.htm

3 Writing Group for the Women's Health Initiative Investigators. Risk and benefits of estrogen plus progestin in healthy postmenopausal women. Principal results from the Women's Health Initiative randomized controlled trial. JAMA 2002;288:321-33.

4 Women's Health Initiative Steering Committee. Effects of conjugated equine estrogen in postmenopausal women with hysterectomy: The women's health initiative randomized controlled trial. JAMA 2004;291:1701-12.

5 Shumaker SA, Legault C, Kuller L, Rapp SR, Thal L, Lane DS, et al. Conjugated equine estrogens and incidence of probable dementia and mild cognitive impairment in postmenopausal women. JAMA 2004;291:2947-58.

6 Shumaker SA, Legault C, Thal L, Wallace RB, Ockene JK, Hendrix SL, et al. Estrogen plus progestin and the incidence of dementia and mild cognitive impairment in postmenopausal women: the women's health initiative memory study: a randomized controlled trial. JAMA 2003:289:2651-62.

7 Rossouw JE, Prentice RL, Manson JE, Wu L, Barad D, Barnabei VM, et al. Postmenopausal hormone therapy and risk of cardiovascular disease by age and years since menopause. JAMA 2007;297:1465 77.

8 National Institute for Health and Clinical Excellence. The guidelines manual. London: National Institute for Health and Clinical Excellence, 2006

9 Harris RP, Helfand M, Woolf SH, Lohr KN, Mulrow CD, Teutsch SM, et al. Current methods of the U.S. Preventive Services Task Force: a review of the process. Am J Prev Med 2001;20:21-35.

\section{Preventing ventilator associated pneumonia}

\section{Oral antiseptic agents should be part of a multi faceted preventive care package}

\section{RESEARCH, p 889}

\section{Christian Brun-Buisson}

professor, Service de Réanimation

Médicale, Centre Hospitalier

Universitaire Henri Mondor, AP-HP,

Université Paris 12, Créteil, France

Christian.brun-buisson@hmn.

aphp.fr

Competing interests: None

declared.

Provenance and peer review:

Commissioned; not externally peer

reviewed.

BMJ 2007;334:861-2

doi:10.1136/bmi.39188.59428280
Pneumonia occurring during mechanical ventilation (ventilator associated pneumonia) is the most common infection acquired by patients in intensive care. Reported rates range from $9 \%$ to $67 \%$ and 4.4 to 15.7 cases per 1000 ventilator days. ${ }^{1}$ In this week's $B M J$, a systematic review by Chan and colleagues ${ }^{2}$ assesses the effect of oral decontamination with antiseptics on ventilator associated pneumonia and mortality in mechanically ventilated adults.

Ventilator associated pneumonia prolongs lengths of stay in intensive care and hospital, and it increases costs of care and possibly increases mortality. ${ }^{34}$ The prevention of this infection is therefore a high priority for infection control in intensive care. ${ }^{5}$

Preventive procedures deal with three broad areas: prevention of cross transmission; upper digestive tract colonisation and the risk of inhalation; and maintenance and care of the artificial and natural airways. ${ }^{5-7}$ Because the oropharynx and upper intestinal tract are the major sources of organisms causing pneumonia in intensive care, they would appear to be good targets for preventive measures.

Many studies have assessed prevention using antimicrobials administered via various routes, alone or combined. "Selective digestive tract decontamination," which uses various combinations of systemic and topical (oropharyngeal and intestinal) antibiotics has generated the largest number of trials, summarised in at least eight successive systematic reviews, including one by the Cochrane group. ${ }^{8}$ In the latest update, which included 36 trials involving 6922 patients, topical and combined systemic antibiotics reduced respiratory tract infections (odds ratio $0.35,95 \%$ confidence interval 0.29 to 0.41 ). Mortality was also reduced with the combination $(0.78,0.68$ to 0.89$)$, but not with topical (intestinal, with or without oropharyngeal) antibiotics alone, despite a comparable effect on rates of pneumonia. ${ }^{8}$ Selective digestive tract decontamination has not been accepted widely ${ }^{5}$ because of controversy about the balance of benefits and risks-particularly on overall use of antibiotics and selection of resistant microorganisms with prolonged use-and uncertainty 


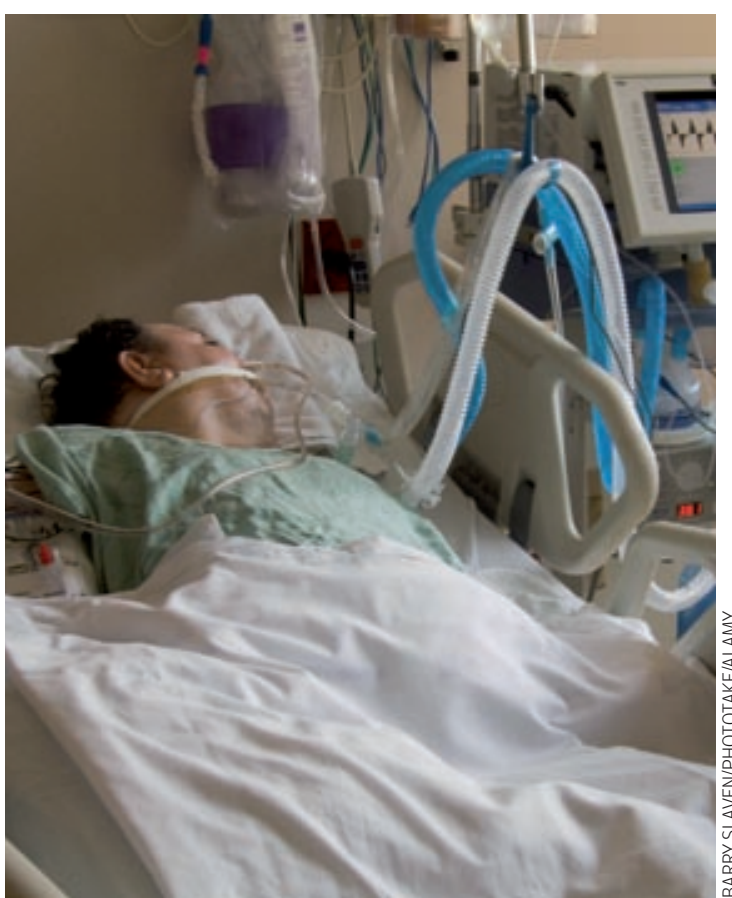

about the respective or added value of components of the antimicrobial regimens tested, whether topical, systemic, or both.

Limiting the application of topical antibiotics to the oropharynx is one option, but too few studies have investigated this question. ${ }^{28}$ In addition, infection rates may be difficult to interpret because of the spill over of antibiotics from the oropharynx into the lower airways. Of even more concern is the presumably high risk of selection of resistant strains in an environment both heavily loaded with microorganisms and exposed to rapid colonisation by hospital acquired organisms. Applying antiseptics rather than antibiotics to the oropharynx might be a solution, but until recently few data were available on this intervention. ${ }^{59}$

The review by Chan and colleagues of seven trials involving 2144 patients found that topical antiseptics significantly reduced the rate of pneumonia (relative risk $0.56,0.39$ to $0.81 ; \mathrm{P}=0.002) .{ }^{2}$ The findings are comparable to those of another recently published review (limited to topical chlorhexidine), which also included seven trials but only 1650 patients. ${ }^{9}$ The two reviews differ by the selection or exclusion of two trials each. Specifically, Chan and colleagues ${ }^{2}$ were able to include the most recently published placebo controlled trial conducted in 954 patients who had undergone cardiovascular surgery, which showed a significant reduction in the rate of pneumonia $(9.3 \% v 15.8 \%$; $\mathrm{P}=0.002)$ with $0.12 \%$ chlorhexidine applied four times daily to the nasal mucosa and oropharynx compared with a placebo similarly applied. ${ }^{10}$ However, as is the case for topical antibiotics only, ${ }^{8}$ the review by Chan and colleagues found that oropharyngeal antiseptics had no impact on mortality $(0.96,0.69$ to $1.33 ; \mathrm{P}=0.82)$ or length of stay in the intensive care unit. ${ }^{2}$

Results varied greatly across the trials included in the review $(\mathrm{P}=0.07),{ }^{2}$ which might in part be explained by differences in design, populations studied (medical versus surgical or mixed), duration of mechanical ventilation, and type and frequency of antiseptics applied. For example, $60 \%$ of patients included in the review ${ }^{2}$ had received cardiac surgery and had a short (mean $<48 \mathrm{~h}$ ) exposure to mechanical ventilation and treatment. ${ }^{10}$ However, in subgroup analyses, the effect size was comparable with short $(<48 \mathrm{~h}$ ) or longer duration of mechanical ventilation, although it was significant only in the larger group of surgical patients. ${ }^{2}$ Further studies should deal with these problems and confirm the efficacy of antiseptics, especially in larger groups of medical patients in intensive care who receive prolonged mechanical ventilation.

Preventing ventilation associated pneumonia is difficult, because of the insertion of an indwelling device within a contaminated area. Only substituting invasive mechanical ventilation with non-invasive ventilation, when appropriate, can circumvent this problem. ${ }^{11}$ However, implementing a group of multifaceted and targeted preventive measures-including education of personnel, semirecumbent positioning of patients, care of ventilator circuit, and no-touch suctioning-can substantially reduce rates of infection. ${ }^{12}$ The data now available, while still limited, suggest that oropharyngeal care with antiseptics may be included in such preventive strategies. However, as is the case for antibiotics, the risk of a long term effect of widespread use of antiseptics on the emergence and spread of bacterial resistance to these agents needs to be considered.

1 National Nosocomial Infections Surveillance (NNIS) System. NNIS report, data summary from January 1992 to June 2004, issued October 2004. Am J Infect Control 2004;32:470-85.

2 Chan EY, Ruest A, Meade MO, Cook DJ. Oral decontamination for prevention of pneumonia in mechanically ventilated adults: systematic review and meta-analysis. BMJ 2007 doi: 10.1136/ bmj.39136.528160.BE.

3 Heyland DK, Cook DJ, Griffith LE, Keenan SP, Brun-Buisson C, for the Canadian Critical Care Trials Group. The attributable morbidity and mortality of ventilator-associated pneumonia in the critically ill patient. Am J Respir Crit Care Med 1999;159:1249-56.

4 Niederman M, Craven DE, Bonten MJ, Chastre J, Craig WA, Fagon JY, et al. Guidelines for the management of adults with hospital-acquired, ventilator-associated, and healthcare-associated pneumonia. Am J Respir Crit Care Med 2005;171:388-416.

5 Tablan OC, Anderson LJ, Besser R, Bridges C, Hajjeh R. Guidelines for preventing health-care-associated pneumonia, 2003: recommendations of $C D C$ and the healthcare infection control practices advisory committee. MMWR Recomm Rep 2004;53:1-36.

6 Cook DJ, De Jonghe B, Brochard L, Brun-Buisson C. Influence of airway management on ventilator-associated pneumonia. JAMA 1998;279:781-7.

7 Dodek P, Keenan S, Cook DJ, Heyland DK, Jacka M, Hand L, et al. Evidence-based clinical practice guideline for the prevention of ventilator-associated pneumonia. Ann Intern Med 2004;141:305-13.

8 Liberati A, D’Amico R, Pifferi S, Torri V, Brazzi L. Antibiotic prophylaxis to reduce respiratory tract infections and mortality in adults receiving intensive care. Cochrane Database Syst Rev 2004; (1):CD000022.

9 Chlebicki MP, Safdar N. Topical chlorhexidine for prevention of ventilator-associated pneumonia: a meta-analysis. Crit Care Med 2007;35:595-602.

10 Segers P, Speekenbrink RG, Ubbink DT, van Ogtrop ML, de Mol BA. Prevention of nosocomial infection in cardiac surgery by decontamination of the nasopharynx and oropharynx with chlorhexidine gluconate: a randomized controlled trial. JAMA 2006;296:2460-6.

11 Girou E, Schortgen F, Delclaux C, Brun-Buisson C, Blot F, Lefort Y, et al. Association of non-invasive ventilation with nosocomial infections and survival in critically ill patients. JAMA 2000;284:2361-7.

12 Babcock HM, Zack JE, Garrison T, Trovillion E, Jones M, Fraser VJ, et al. An educational intervention to reduce ventilator-associated pneumonia in an integrated health system: a comparison of effects. Chest 2004;125:2224-31. 